\title{
Measurable predictors of hermeneutic empathy: relationship focus and emotional intelligence
}

\author{
Marina Ragulina ${ }^{1, *}$ \\ ${ }^{1}$ Pacific National University, Khabarovsk, Russia
}

\begin{abstract}
In modern scientific literature today, two areas of study of empathy have emerged: empathy as compassion and an emotional response to the situation of the Other and empathy as a "tool of knowledge". The widespread use of this concept in advisory practice prompts to clarify and concretize this important concept. The author clarifies the Rogerian concept of empathy, which is widespread in Russian psychology. The paper presents a pilot study of two groups of psychology students, one of which is attuned to relationships as an important criterion for the effectiveness of counselling, the other group considers the client's motivation to be significant. The study of emotional empathy and emotional intelligence confirmed the hypothesis that students who are attuned to relationships will have lower emotional empathy, while emotional intelligence as an indirect indicator of hermeneutic empathy is higher, and vice versa in the second group. The study showed the statistical significance of these differences on some scales and on the manifestation of emotional empathy. The paper proposes a substantiation for this phenomenon. Also, the ability for hermeneutic empathy as another way of non-verbal communication can be indirectly confirmed by the diagnosis of emotional intelligence.
\end{abstract}

\section{Introduction}

In the modern conceptual thesaurus of psychology, the concept of "empathy" is one of the most frequently used, but at the same time it is difficult to understand, if not to say elusive for concretization and definition of the boundaries beyond which the content space of something else begins. The meaningful ambiguity and vagueness of the concept of "empathy" prompts us to turn again to its theoretical analysis and the search for empirical argumentation.

If we turn to the history of the scientific discussion of this concept, then we can conditionally trace two directions, one of which designates empathy as a non-verbal "cognitive tool" of consciousness for comprehending the Other, but also empathy is considered as an emotional tendency of a person in empathy, providing and supporting communication.

The word "empathy" according to the "An Etymological Dictionary of Modern English"

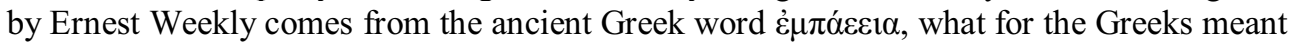
physical affection or passion, the word is cognate with the word "pathos" غ่v $\pi$ óoo - in

\footnotetext{
* Corresponding author: ragulina@inbox.ru
} 
passion or in suffering. For the German language, this term was adapted by Hermann Lotze and Robert Vischer, and the word Einfühlung (feeling in...) was introduced into everyday life. The term was then brought back into English again by Vernon Lee, who explained it as "compassion, with feeling", to denote the phenomenon of our detection of feelings in the form that we perceive. The term einfühlung was officially translated by psychologist Edward B. Titchener in 1909 into the English word empathy and was used in his work "Introspection and empathy" in 1909. Titchener, obviously, carefully selected a term that would express the meaning of his method of introspection and, generally, would be successfully integrated into his theory of the structure of consciousness.

The word came to Russian psychology together with the interest of Russian psychologists in the humanitarian paradigm in science and in the theoretical approach of C. Rogers in counselling as a social practice.

It can be assumed that for Rogers, the concept of empathy in the consultative space of the development of relations had a meaning close to Titchener's understanding of this phenomenon. Actually, the idea of empathy developed in the mainstream set by Titchener.

In one of his early systemic works, where Carl Rogers analyzes his own experience and his worldview aspects related to the organization of the consultant's practice, in "Counseling and Psichotherapy: newer concepts in practice", published in 1942, he does not mention the phenomenon of empathy in any way, but writes more about the limitations that affect the creation of the atmosphere of the therapeutic relationship and create new non-directive interaction opportunity.

Non-directiveness of the approach means that the consultant does not use social templates that are usual for building relationships, containing hierarchical attitudes and power, but while remaining cordial, approachable and sincere, he still deliberately limits both his responsibility and his affective attachment (dependence on relationships).

Karyagina T.D., the author who studied and presented in the most detail the theory of K. Rogers in his works, rightly notes that it seems that no own general psychological theory of empathy is presented in Rogers's works, but nevertheless he described it in detail as a method of psychotherapy and counselling [1,2]. It's hard to argue with that; in later articles, Rogers, where poetically figurative, for example, in article dd. 1957 "The Necessary and Sufficient Conditions of Therapeutic Personality Change", where in the scientific style, as in the article dd. 1975 "Empatic: an unappreciated way of being", reveals and analyzes the content of this phenomenon.

In article dd. 1975 Rogers writes that empathy is one of the most important conditions for personality change in psychotherapy (in fact, which is the strategic goal of the meeting of two individuals), and he tells of empathic understanding, emphasizing the interpersonal sense of empathy. Perhaps even referring to this term, through it, he emphasizes interpersonal or person-to-person meaning of empathy. The consultant, being in a voluntarily limited interaction, but experiencing friendly and expressively available feelings towards the client, allows him to cope with his resistance to moral prohibitions and without fear of punishment, also open up in his subjective experience of his own "being".

Empathic understanding acts as a way of penetrating (above Rogers also uses the word immersion) in that part of the relationship that develops from the client's side. A unique dyad arises - a therapist who is steadily immersed in the client's feelings and sensations, as if they are his feelings, but without dependence on them, and the client is immersed in his feelings and connected by them and dependent on them.

In this unique situation, the therapist acts as a facilitator, encouraging the client to carefully and caringly stop and comprehend, and not slip through 'his own Being at this point in time'. He cites the words of one of his clients, clarifying the meaning of what is happening between, comparing the therapist's empathy to a "ray of the sun" illuminating the jungle of consciousness. 
W.Keil, the German psychotherapist, in his work "Hermeneutic Empathy in ClientCentered Therapy", published in 1996 in Cologne, introduces the concept of "hermeneutic empathy", following Rogers' ideas about the necessary conditions for effective counseling and personality theory.

Drawing on Rogers' ideas and supporting the therapist's idea of the therapist's hermeneutic empathic understanding of the client, he writes that psychotherapy is supposed to work with the latent non-authentic or, in other words, the "depth-psychological" aspects of consciousness. Inauthentic, otherwise incongruent, experiences that cannot be accepted by the therapist and cannot be answered with a positive attitude, i.e. the therapist, with all his deep empathy for the client's suffering, does not support his incongruence. Rogers' theory of therapy does not really contain such a concept, but it does arise when we explicitly include Rogers' theory of personality. In Rogers' theory of therapy, the idea of unconditional positive attitude and empathic understanding is extended to the entire given client's experience. The entire unique inner world of the client should be perceived positively and with understanding. At the same time, in personality theory, the congruence-incongruence of the therapist's self is determined by how the therapist encounters the client's defensive behavior and the experience he denies. This would mean that the therapeutic effort should be directed primarily towards the phenomenon of the defending self and the experience it denies, and therefore towards the understanding of incongruence.

In his system of conditions for effective therapeutic work, Rogers put the congruence of relationships associated with the congruence of relationship partners (the more congruent they are, the more congruence in their relationship ("congruence" - the literal translation is coincidence)). If we talk about relationships, then congruence can be understood as the coincidence of the experience of one partner and the reaction to it of another partner in communication. In everyday life, people are often incongruent, adhering to the rules of social communication and politeness. A good literary example of congruent reactions is the hero of Dostoevsky's novel "The Idiot", Prince Myshkin, who shows deep empathy for the heroes (in Rogers' understanding) and responds to their experiences congruently, which at first completely discourages them, but then this allows their true reactions (congruent) to arise. His empathy is fully hermeneutic, every time he plunges into the emotional experience of his interlocutor, surrendering to him not unconsciously, but guided by a well-recognized moral task.

Introducing the idea of empathic understanding into his thesaurus, Rogers probably studied the work of Titchener, whose empathy "is introduced as a scientific method for the study of consciousness in areas where experimental psychology and experiment are limited in their capabilities.

Titchener believed that the phenomenon when an observer not only sees certain visual images of different states of consciousness, but they are actualized in his bodily (muscular) mind (mind's muscles) and he feels them, and there is a simple example of empathy, similar to German "einfühlung". Surprisingly, the idea of individuality, which is determined by meanings, i.e. the meaning of what is happening (why two people, placed in the same conditions, think and feel differently) echoes the statement of L.S. Vygotsky that the individuality of an experience is determined by a person's unique response to a typical basic emotion. Titchener saw empathy as a method or tool of introspection in the study of human thinking and its components that determine individuality. He wrote in his lectures, referring to the experiments of Bühler, when the experimenter and the volunteer observer, interacting, can, using the experimenter's empathy in the observer's introspection, understand the meanings of their own thinking through emotionally colored images.

Bühler's examples are in many ways similar to the situation of psychological counseling, when a counselor asks a question and tries to penetrate the client's experiences, actualized by 
this question. And then it becomes clear Rogers' idea of congruent and incongruent empathy of the consultant in relations with the client and the development of this idea in Keil's works.

Just as Titchener wrote that the ability to introspection must be developed, which implies the ability to focus on one's own feelings, feelings and thoughts and to analyze them, so hermeneutic empathy also needs to be developed and trained in order to strive for a congruent relationship with the client, which allows him, as an observer of Bühler, to delve deeper into the nature of his experience.

The development of psychology introduces new concepts, today the idea of human kinesthetics as the primary source of his integrity in the content of consciousness is not so popular. Today, the theory of emotional intelligence is trying to solve such a universal problem of discovering the interconnection of different-level systems of consciousness.

Hermeneutic empathy - the term of the humanistic paradigm in psychology, which does not set itself the task of measuring human qualities by means of diagnostic methods, $\Pi$ believing that a person is complex and his subjectivity is elusive and phenomenological. There are few questionnaires created within the framework of humanistic psychology.

Emotional intelligence is a concept that was born in the direction of psychology, which studies human behavior and adaptation.

Nevertheless, some of the elements that make up the structure of emotional intelligence at the same time provide an opportunity to measure hermeneutic empathy. For example, a study by the Degtyarev [7] showed that emotional intelligence correlates with the feeling of a psychological boundary, which brings it closer to hermeneutic empathy as understood by C. Rogers and V. Keil. Our attempt to link emotional intelligence and hermeneutic empathy does not seem entirely hopeless to us.

We can assume that hermeneutic empathy manifests itself on the basis of skills: to emotional self-knowledge; to awareness of the connection between cognitive stimulus processing (awareness) and emotional response; to the detection of preferred emotional reactions, whether they are associated with temperament or with adaptation to socio-cultural characteristics of existence; and also to the conscious choice of the method of reaction that is most effective in a stressful situation and, therefore, is associated with emotional intelligence.

Hermeneutic empathy of the consultant - it is the ability to stay in complex, maybe rejecting and devaluing, from the client's side, relationship, not to resort to an equivalent answer, and not to ignore the client's dangerous experiences, but on the contrary with all the compassion and friendliness that the counselor is capable of encouraging the client to explore the internal sources of his reactions.

The most productive in combining cognitive and emotionally motivational functions of consciousness is the model of emotional intelligence by M. Seidner et al. [3]. It can be argued that control over social behavior and emotional stability are properties of the temperamental level, and in general, the model relies on a behavioral approach, but it considers emotional intelligence as a phenomenon, which simulates the behavior through the skills system, provided by emotional self-regulation. Based on the model of Seidner et al., D.V. Lyusin $[4,5,6]$ describes an integrated structure of emotional intelligence, which includes a system of skills, in one way or another related to hermeneutic empathy, for example, a good awareness of one's own and others' emotions, sensitivity and intuition in recognizing emotional states, a conscious choice of behavioral manifestations of emotions.

In contrast to the hermeneutic empathy according to Mehrabian [9] there is a natural personality characteristic, manifested through three main manifestations: emotional response, the ability to join, and sensitivity to rejection.

Belyaeva V.N., Koryagina T.D. call such an emotional response the therapist's empathic involvement; having his own similar experience, the therapist empathizes internally, emotionally responds, emotionally resonates with the client [10]. 
Mehrabian viewed empathy as a quality that enables communication on a non-verbal level; in his famous formula $7 \%-38 \%-55 \%$, only $7 \%$ of communication is occupied by words and the rest are non-verbal forms, most of all bodily. But can this natural characteristic develop into hermeneutic "understanding" empathy if this ability of emotional response is "connected" to the system of awareness? Or are they phenomena of a different nature?

\section{Materials and Methods}

In our study, we set ourselves the goal of discovering the connection between empathy as an emotional response to a relationship with another person and emotional intelligence as a "tool" for cognition and awareness of the content and nature of these relationships, an indirect indicator of hermeneutic empathy. As the respondents of the sample were invited students psychologists studying in the 3rd and 4th years of bachelor's degree in the "Psychology" direction of Pasific National University, a total of 65 young men and women, whose average age was 21.7 years. At the first stage, they were offered small questionnaires, in which, among the questions of a personal nature: "Are you going to work as a consultant?" "Do you like studying psychology?" there were also special questions: "What do you think is more important for effective counseling: relationship building or client motivation?" Thus, two groups were identified: one group - these are the respondents who identified the building of relationships as more important in counseling, the second group are those respondents who considered the client's motivation more important.

It can be assumed that respondents who chose relationship significance attach more value to relationships and may be more attuned to developing relationship building skills. The same respondents who believe that the client's motivation is most important in counseling may believe that if the client has a stable motivation, then it will serve as a guarantee of relationships and, for various reasons (weak ability to take responsibility, lack of selfconfidence, etc.) are not too tuned in to internal work to develop the ability to establish sustainable relationships.

Our hypothesis was that the group of respondents who chose relationships will have higher scores of emotional intelligence and lower scores of emotional empathy, and the group of respondents who chose the opposite motivation of the client may have very high emotional sensitivity, but lower indicators of emotional intelligence.

To measure the tendency towards emotional empathy, we used the updated (dd 1996) Mehrabian test, which consists of 30 statements -15 positives and 15 negatives, with a rating scale from -4 (very strong disagreement) up to +4 (very strong agreement). Hence the name of the new test variation Balanced Emotional Empathy Scale or BEES. Its results correlate quite strongly with the original EETS $(0.77)$ and have high internal consistency and reliability (alpha- Cronbach - 0.87).

As we noted above, sometimes the theoretical approaches describing emotional intelligence have a lack of clear statements, that are replaced by a list of desirable qualities. Therefore, we decided on M. Zeidner et al. model [3], including not only the individual differences of different people in the manifestation of emotions, but also describes emotional abilities as a system associated with the socio-cultural context that influences emotional behavior. Based on this model, D.V. Lyusin [4,5,6] identified three groups of factors on which the degree of development of the Emotional Intelligence of a person depends: cognitive abilities (speed and precision of emotional information processing), ideas about emotions (both in terms of values and the importance attributed to them as sources of information about oneself and others), special features of emotionality (emotional stability, emotional sensitivity, etc.)

An interesting study by M.V. Vetluzhskaya with coauthors, in which they study emotional intelligence and empathy according to the Hall model, in which there are scales 
that intersect with the scales of emotional intelligence according to the model of D.V. Lyusin, for example, "emotion management". Accordingly, in their study, emotional intelligence and empathy correlate well [8].

All of the above characteristics cannot be fully attributed to hermeneutic empathy, it still presupposes some kind of effort, the skill to keep oneself in the context of relationships, regardless of personal social security, and at the same time, while managing your emotional state, maintain a friendly attitude towards the Other, which in existential-humanistic approaches is called acceptance. But, nevertheless, this model contains predictors of hermenical empathy, that is, it can be assumed that students studying in the direction of "Psychology" already have some abilities that provide it with the manifestation of this phenomenon. Therefore, we chose the Lyusin questionnaire for the diagnosis of emotional intelligence.

\section{Results}

All respondents divided into two groups based on the choice of the most significant criterion for the effectiveness of counseling - group 1 (choice of relationship) and group 2 (choice of client's motivation) were tested using two methods - "Emotional Intelligence" by D.V. Lyusin, EmIn in reduction, and Mehrabian's "Balanced Emotional Empathy Scale", BEES in reduction.

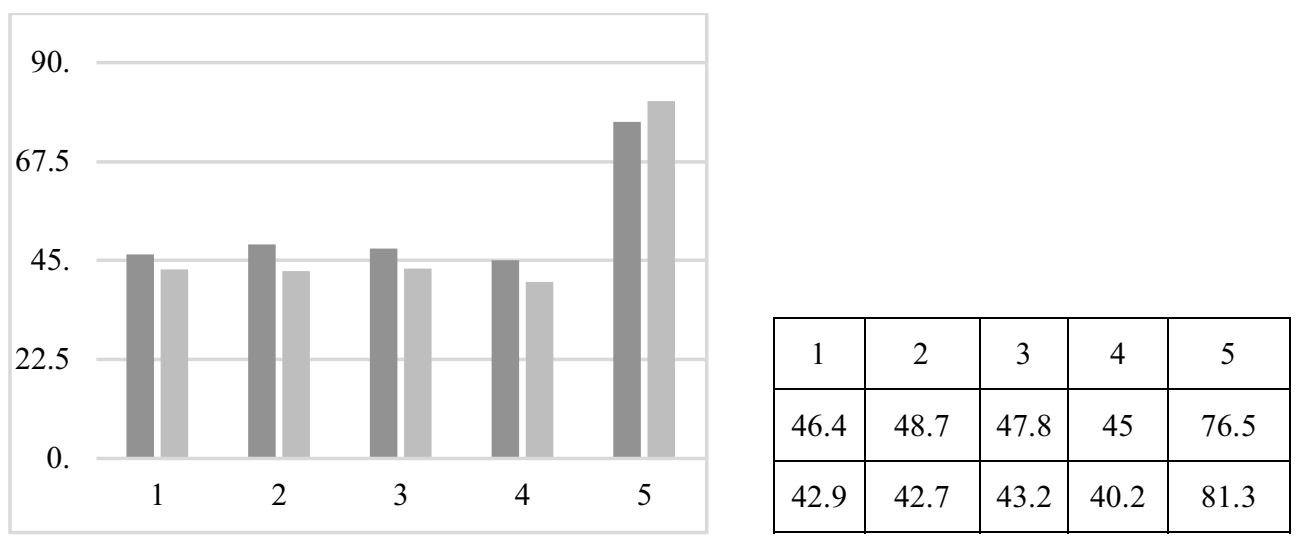

1 - scale of interpersonal emotional intelligence (ability to understand and manage other people's emotions);

2 - scale of inside emotional intelligence (ability to understand and manage your own emotions);

3 - scale of understanding emotions;

4 - emotion management scale;

5 - overall measurement score for emotional empathy.

Fig. 1. Histogram of the distribution of average results in groups 1 and 2: 1 - the group that selected the relationship (a darker column), 2 - the group that selected the client's motivation.

Comparison of raw scores shows that our hypothesis was not unreasonable. Indeed, we see that emotional intelligence is higher for the group of students who choose the importance of the relationship between the client and the counselor, and emotional empathy is higher for students who choose the client's motivation as a more important condition in counseling.

In order to check the reliability of differences in groups 1,2 on the scales and subscales of the two methods, we used Student's T-criterion for two independent samples.

Table 1. Results of calculating the T-criterion based on data from two groups obtained by EmIn and BEES. 


\begin{tabular}{|c|c|c|c|c|c|c|c|c|c|c|c|}
\hline & $\begin{array}{c}\text { averag } \\
\text { e value } \\
-1\end{array}$ & $\begin{array}{l}\text { averag } \\
\text { e value } \\
-2\end{array}$ & $\begin{array}{c}\text { T- } \\
\text { criterio } \\
n\end{array}$ & $\begin{array}{l}\text { c } \\
\text { c }\end{array}$ & $\mathbf{p}$ & $\begin{array}{l}N \\
1\end{array}$ & $\begin{array}{l}\mathbf{N} \\
2\end{array}$ & $\begin{array}{c}\text { Standar } \\
\text { d } \\
\text { deviatio } \\
\text { n 1 }\end{array}$ & $\begin{array}{c}\text { Standar } \\
\text { d } \\
\text { deviatio } \\
n-2\end{array}$ & $\begin{array}{c}\text { F- } \\
\text { relative } \\
\text { varianc } \\
\text { e. }\end{array}$ & $\begin{array}{c}\text { p - } \\
\text { dispers }\end{array}$ \\
\hline 1 & $\begin{array}{l}26.8787 \\
9\end{array}$ & $\begin{array}{l}23.8750 \\
0\end{array}$ & $\begin{array}{l}2.6828 \\
7\end{array}$ & $\begin{array}{l}6 \\
3\end{array}$ & $\begin{array}{l}0.00931 \\
2\end{array}$ & $\begin{array}{l}3 \\
3\end{array}$ & $\begin{array}{l}3 \\
2\end{array}$ & 4.99223 & 3.95743 & $\begin{array}{l}1.59133 \\
4\end{array}$ & $\begin{array}{l}0.19911 \\
1\end{array}$ \\
\hline 2 & $\begin{array}{l}19.6363 \\
6\end{array}$ & $\begin{array}{l}19.0000 \\
0\end{array}$ & $\begin{array}{l}0.8829 \\
7\end{array}$ & $\begin{array}{l}6 \\
3\end{array}$ & $\begin{array}{l}0.38061 \\
2\end{array}$ & $\begin{array}{l}3 \\
3\end{array}$ & $\begin{array}{l}3 \\
2\end{array}$ & 3.44436 & 2.21432 & $\begin{array}{l}2.41955 \\
7\end{array}$ & $\begin{array}{l}0.01576 \\
4\end{array}$ \\
\hline 3 & $\begin{array}{l}14.9090 \\
9\end{array}$ & $\begin{array}{l}13.1875 \\
0\end{array}$ & $\begin{array}{l}1.7455 \\
5\end{array}$ & $\begin{array}{l}6 \\
3\end{array}$ & $\begin{array}{l}0.08576 \\
4\end{array}$ & $\begin{array}{l}3 \\
3\end{array}$ & $\begin{array}{l}3 \\
2\end{array}$ & 3.59134 & 4.33618 & $\begin{array}{l}1.45780 \\
9\end{array}$ & $\begin{array}{l}0.29411 \\
0\end{array}$ \\
\hline 4 & $\begin{array}{l}12.5151 \\
5\end{array}$ & $\begin{array}{l}10.1875 \\
0\end{array}$ & $\begin{array}{l}2.1188 \\
9\end{array}$ & $\begin{array}{l}6 \\
3\end{array}$ & $\begin{array}{l}\mathbf{0 . 0 3 8 0 4} \\
8\end{array}$ & $\begin{array}{l}3 \\
3\end{array}$ & $\begin{array}{l}3 \\
2\end{array}$ & 5.53467 & 2.86736 & $\begin{array}{l}3.72578 \\
7\end{array}$ & $\begin{array}{l}\mathbf{0 . 0 0 0 4 1} \\
7\end{array}$ \\
\hline 5 & $\begin{array}{l}21.5757 \\
6\end{array}$ & $\begin{array}{l}19.2500 \\
0\end{array}$ & $\begin{array}{l}1.7160 \\
3\end{array}$ & $\begin{array}{l}6 \\
3\end{array}$ & $\begin{array}{l}0.09107 \\
1\end{array}$ & $\begin{array}{l}3 \\
3\end{array}$ & $\begin{array}{l}3 \\
2\end{array}$ & 5.78268 & 5.11166 & $\begin{array}{l}1.27977 \\
9\end{array}$ & $\begin{array}{l}0.49428 \\
6\end{array}$ \\
\hline 6 & $\begin{array}{l}46.3636 \\
4\end{array}$ & $\begin{array}{l}42.9375 \\
0\end{array}$ & $\begin{array}{l}1.9934 \\
0\end{array}$ & $\begin{array}{l}6 \\
3\end{array}$ & $\begin{array}{l}0.05055 \\
2\end{array}$ & $\begin{array}{l}3 \\
3\end{array}$ & $\begin{array}{l}3 \\
2\end{array}$ & 8.09250 & 5.47096 & $\begin{array}{l}2.18795 \\
4\end{array}$ & $\begin{array}{l}0.03181 \\
9\end{array}$ \\
\hline 7 & $\begin{array}{l}48.6969 \\
7\end{array}$ & $\begin{array}{l}42.7500 \\
0\end{array}$ & $\begin{array}{l}1.8136 \\
2\end{array}$ & $\begin{array}{l}6 \\
3\end{array}$ & $\begin{array}{l}0.07449 \\
9\end{array}$ & $\begin{array}{l}3 \\
3\end{array}$ & $\begin{array}{l}3 \\
2\end{array}$ & $\begin{array}{l}15.1151 \\
5\end{array}$ & $\begin{array}{l}10.9161 \\
0\end{array}$ & $\begin{array}{l}1.91729 \\
9\end{array}$ & $\begin{array}{l}0.07320 \\
2\end{array}$ \\
\hline 8 & $\begin{array}{l}47.7575 \\
8\end{array}$ & $\begin{array}{l}43.1875 \\
0\end{array}$ & $\begin{array}{l}2.0812 \\
7\end{array}$ & $\begin{array}{l}6 \\
3\end{array}$ & $\begin{array}{l}0.04147 \\
9\end{array}$ & $\begin{array}{l}3 \\
3\end{array}$ & $\begin{array}{l}3 \\
2\end{array}$ & 9.35424 & 8.29861 & $\begin{array}{l}1.27059 \\
4\end{array}$ & $\begin{array}{l}0.50697 \\
6\end{array}$ \\
\hline 9 & $\begin{array}{l}45.0000 \\
0\end{array}$ & $\begin{array}{l}40.1875 \\
0\end{array}$ & $\begin{array}{l}1.8036 \\
2\end{array}$ & $\begin{array}{l}6 \\
3\end{array}$ & $\begin{array}{l}0.07607 \\
2\end{array}$ & $\begin{array}{l}3 \\
3\end{array}$ & $\begin{array}{l}3 \\
2\end{array}$ & $\begin{array}{l}11.8030 \\
7\end{array}$ & 9.55270 & $\begin{array}{l}1.52664 \\
5\end{array}$ & $\begin{array}{l}0.24191 \\
6\end{array}$ \\
\hline $\begin{array}{l}1 \\
0\end{array}$ & $\begin{array}{l}76.4848 \\
5\end{array}$ & $\begin{array}{l}81.2812 \\
5\end{array}$ & $\begin{array}{l}- \\
3.6778 \\
8\end{array}$ & $\begin{array}{l}6 \\
3\end{array}$ & $\begin{array}{l}0.00048 \\
9\end{array}$ & $\begin{array}{l}3 \\
3\end{array}$ & $\begin{array}{l}3 \\
2\end{array}$ & 2.45104 & 7.06757 & $\begin{array}{l}8.31460 \\
3\end{array}$ & $\begin{array}{l}0.00000 \\
0\end{array}$ \\
\hline
\end{tabular}

We see that statistically significant differences still exist at $\mathrm{p}<0,01$, on such subscales as understanding other people's emotions (1), expression control (4), and on the general scale of "understanding your own and others' emotions" (8), as well as in the second group (choice of motivation) the average emotional response rate (10) is significantly higher. A contradiction is revealed; students who describe themselves as more emotionally responsive also respond that they are less likely to understand other people's emotions and their own emotions, and control emotional expression.

Surprisingly, this data, in our opinion, correlates with the data obtained in one interesting old experiment of Galper R.E. [12]. Those observers who were emotionally included, i.e. tried to understand the emotional nature of the actor's actions or, as they are called in the article, "empitizing" viewers made fewer personal descriptions, than those observers who were instructed to "understand the situation," or "non-empathizing spectators," who relied more on personal attributions in their descriptions of what was happening.

But Galper R.E. did not measure empathy, she set up observers like Titchener or Roger to immerse themselves in the subjective world of the one they were observing, to perform a complex act of self-alienation and immerse themselves in the emotional world of the Other, thus transforming empathy into a cognitive function (hermeneutic empathy), those who tried 
to grasp aspects of the situation could only discover cause-and-effect relationships on the basis of their own experience, through an emotional response to similar things, bringing in many personal explanations (emotional empathy).

More recent confirmation of the nature of hermeneutic empathy suggests research of Elena V. Chistova [13]. She studied the reactions of simultaneous interpreters and came to the conclusion about productive and unproductive empathy. Productive empathy is included in the system of professional abilities of the translator and actualizes translation partners in case of cognitive dissonance to join forces, which improves the result, unproductive empathy not only does not contribute to the creation of a unified cognitive field, but even has destructive tendencies. We liked this study because the psychologist also acts as a bit of a 'translator' in the interaction with the client. An example from another methodological area of psychology very indicatively correlates with the concept of hermeneutic empathy in the context of the client's incongruent behavior.

Table 2. Spearman rank correlations based on group 1 data (relationship selection), $\mathrm{p}<0.05$.

\begin{tabular}{|c|l|l|l|l|l|}
\hline & \multicolumn{1}{|c|}{$\operatorname{var1}$} & \multicolumn{1}{|c|}{ var 2 } & \multicolumn{1}{|c|}{ var 3 } & \multicolumn{1}{|c|}{ var 4 } & var 5 \\
\hline var 1 & & 0.639103 & 0.623671 & 0.616378 & \\
\hline $\operatorname{var}$ 2 & 0.639103 & & 0.789169 & 0.712032 & \\
\hline $\operatorname{var}$ 3 & 0.623671 & 0.789169 & 1.000000 & 0.579192 & \\
\hline $\operatorname{var}$ 4 & 0.616378 & 0.712032 & 0.579192 & & \\
\hline var 5 & & & & & \\
\hline
\end{tabular}

Table 3. Spearman rank correlations based on group 2 data (client motivation selection) $\mathrm{p}<0.05$.

\begin{tabular}{|c|l|l|l|l|l|}
\hline & \multicolumn{1}{|c|}{$\operatorname{var}$ 1 } & \multicolumn{1}{|c|}{$\operatorname{var}$ 2 } & \multicolumn{1}{|c|}{$\operatorname{var}$ 3 } & \multicolumn{1}{|c|}{$\operatorname{var}$ 4 } & \multicolumn{1}{|c|}{ var 5 } \\
\hline $\operatorname{var} 1$ & & & 0.791446 & 0.815693 & \\
\hline $\operatorname{var}$ 2 & & & & & \\
\hline $\operatorname{var}$ 3 & 0.791446 & & & 0.766409 & 0.524990 \\
\hline $\operatorname{var}$ 4 & 0.815693 & & 0.766409 & & \\
\hline $\operatorname{var}$ 5 & & & 0.524990 & & \\
\hline
\end{tabular}

Empathy questionnaires do not provide an objective picture of the level of empathy of people who answer the test questions. Rather, the respondents' ideas about the self-image are revealed. [11]

A qualitative explanation can be found in Jung's extraversion-introversion theory [14]. Empathy, as the most archaic adaptive function of consciousness, seeks to fill the empathized subject with its own subjective content, and for this, the empathizing subject performs the unconscious act of "extinguishing the effectiveness", by creating an "empty object" but without revealing this, that is, for the empathizing subject, the object seems to live and speak on behalf of itself. Empathy is carried out through the transfer mechanism and, in fact, there is extraversion, according to Jung. It seems that he was referring to emotional empathy. The same mechanism of empathy is carried out in the symbiotic "mother-child" dyad, when the mother, by external signs, determines the emotion of the child and at the same time gives 
meaning to this emotion at the child.

\section{Discussion}

To determine the most significant scales in the structure of emotional intelligence, we used the statistical procedure for calculating the Spearman correlation coefficient, this made it possible to find in the first group significant strong correlations between the scales of the Lyusin questionnaire and the absolute absence of a relationship between indicators of emotional intelligence and emotional empathy. Variable 1 - the scale for understanding other people's emotions is associated with significant correlations with intrapersonal intelligence, including recognition of their emotions, understanding of the reasons and the ability to verbal description, it is significant that interpersonal intelligence in this group correlates with intrapersonal intelligence and with the ability to manage with others' and their own emotions. The Emotion Management Scale, according to Lyusin, involves the ability to reduce the intensity of unwanted emotions, the ability to evoke certain emotions in other people, actually to influence on the emotional nature of the relationship. The lack of correlations between the scales of emotional intelligence and emotional empathy may indicate that the process of realizing one's emotional nature significantly reduces unconscious emotional sensitivity. It can be assumed that in the first group, emotional intelligence develops as a systemic phenomenon of interrelated elements: the ability to understand and recognize one's own emotional experiences, personal experience of self-immersion allows one not to merge with the emotional experience of other people, but at the same time to feel and recognize the experience of the Other. In any case, we are talking about the fact that unconscious ways of adaptation give way to choose, which occupies an ever-larger space of consciousness.

In the second group, we see fewer number of correlations. The scale of interpersonal emotional intelligence correlates, as a result of self-description, with the ability to understand one's own and other people's emotions and to manage them. It can be assumed that the internal task that unites the second group is associated with the ability to control emotions. We see that their scale of understanding emotions significantly correlates with emotional empathy. Most likely, the general configuration of correlations in this group suggests that the respondents of this group have a high level of sensitivity to the emotional reactions of the Other and that emotion control still has adaptive, protective forms.

\section{Conclusions}

We can assume that the phenomenon that is designated as emotional empathy has a natural basis and is consistent with Jung's ideas about its adaptive nature and has an external orientation towards relationships, which Jung called extroversion. In general, people who are attuned to relationships with others go study in counseling. Hermeneutic empathy is a transition to a different emotional status, reflected in the concept of emotional intelligence, expansion of the zone of awareness of the emotional state and the choice of the most effective way of responding. But the important point, the definition of the moral purpose of the choice remains hidden, therefore, Lyusin rightly notes that emotions control can also be manipulative. Karyagina T.D. [15], speaking about the professionalization of empathy, also distinguishes two of its aspects: empathy as a natural function and empathy as an ability. As a natural function, empathy is possibly the basis for the development of ability as a conscious and controlled process.

\section{References}


1. T.D. Karyagina, Consultative psychology and psychotherapy 24(5), 178-204 (2016) https://doi.org/10.17759/cpp.2016240510

2. F.E. Vasilyuk, T.D. Karyagina, Counseling psychology and psychotherapy 25(3), 11-32 (2017) doi:10.17759/cpp.2017250302

3. M. Zeidner, G. Matthews, R.D. Roberts, C. McCann, Human Development 46, 69-96 (2003) https://www.researchgate.net/publication/247701754_Development_ of_Emotional_Intelligence_Towards_a_Multi-Level_Investment_Model

4. E.G. Shevyreva, I.V. Fedosova, Bulletin of Science and Practice 9(10), 264-269 (2016) DOI: 10.5281 /zenodo.154323?

5. A. Degtyarev, Electronic journal "Psychological Science and Education" DOI: $10.17759 / 2015050303$

6. D.V. Lyusin, Psychological diagnostics 4, 3-22 (2006) https://www.researchgate.net/publication/311706448_Novaa_metodika_dla_izmerenia_emocionalnogo_intellekta_oprosn ik_EmIn

7. A.V. Degtyarev, D.I. Degtyareva, Psychology and law 7(4), 92-105 (2017) doi:10.17759/psylaw.201707040

8. M.V. Vetluzhskaya, A.A. Abramova, K.G. Serdakova, E.E. Bykova, R.S. Khammatova, R.V. Shurupova, Integration of education 23.3(96), 404-422 (2019) DOI: $10.15507 / 1991-9468.096 .023 .201903 .404-422$

9. A. Mehrabian, N. Epstein, Journal of Personality 40, 525-543 (1972) https://doi.org/10.1111/j.1467-6494.1972.tb00078.x

10. V.N. Belyaeva, T.D. Karyagina, Counseling Psychology and Psychotherapy 27(4), 117-135 (2019) DOI: 10.17759/cpp.2019270408

11. M.P. Lazarescu, The Structure and Dynamics of the Teacher's Empathic Behavior https://doi.org/10.1016/j.sbspro.2013.04.341

12. E. Galper Ruth, Journal of Research in Personality 10(3), 328-335 (1976) https://doi.org/10.1016/0092-6566(76)90022-2

13. E.V. Chistova, Journal of the Siberian Federal University. Series: Humanitarian sciences 13(3), 375-384 (2020) DOI: 10.17516/1997-1370- 0560

14. E.Yu. Kleptsova, A.V. Vlasova, Scientific-methodical electronic journal Concept 6, 614 (2017) DOI: 10.24422/MCITO.2017.6.6443

15. T.D. Karyagina, Consultative psychology and psychotherapy 23(5), 235-256 (2015) https://doi.org/10.17759/cpp.2015230511 